\title{
Recent trends in histopathological spectrum of malignancies among females in western Maharashtra
}

\author{
Charusheela R. Gore' ${ }^{1}$, Indranil Dey ${ }^{2, *}$, Harsh Kumar ${ }^{3}$, Kushal Shah ${ }^{4}$, Ishita Gulati ${ }^{5}$ \\ ${ }^{\mathbf{1}}$ Professor, ${ }^{\mathbf{2 , 4 , 5}}$ Resident, ${ }^{3}$ Professor and HOD, Dept. of Pathology, Dr. D.Y. Patil Medical College, Hospital and Research Centre, \\ Pune, Maharashtra \\ *Corresponding Author: Indranil Dey \\ Email: drindranildey@gmail.com
}

Received: $15^{\text {th }}$ February, 2018

Accepted: $25^{\text {th }}$ May, 2018

\begin{abstract}
Introduction: Aim of this study is to evaluate the histopathological spectrum of female malignancies with a motive to understand the prevalent trends of this complex disease.

Materials and Methods: This was a retrospective and prospective study carried over a period of three years. All female patients with histopathologically confirmed malignancies were included in the study.

Result: Total of 1016 cases of malignant lesions were included of which majority were in age group of 40 to 69 years. Breast was the commonest site for primary malignancies followed by cervix. Oropharyngeal squamous cell carcinoma ranked third while colorectal carcinomas emerged as the fourth most prevalent malignancy followed by ovarian cancer. Infiltrating duct carcinoma of the breast was the commonest histopathologic type of malignancy. Majority of the cervical and oropharyngeal cancers were squamous cell type. Colorectal adenocarcinoma was the most common malignancy in the GI tract. Among skin malignancies, squamous cell carcinoma were the most prevalent type followed by basal cell carcinoma and malignant melanoma. Adenocarcinomas were the commonest lung lesions while papillary carcinoma was the most prevalent thyroid malignancy. Transitional cell cancers were the most frequent urinary bladder lesions while renal cell carcinomas were most common kidney malignancy.

Conclusion: In spite of many recently developed diagnostic modalities; histopathological examination remains the gold standard for the diagnosis of malignant lesions. Hospital based Cancer Registries should be established since they provide data which can prove to be an invaluable tool to understand and plan effective remedial measures in the battle against cancer.
\end{abstract}

Keywords: Histopathological spectrum, Malignancies in Females, Western Maharashtra.

\section{Introduction}

Malignancies have emerged as the leading cause of morbidity and mortality among females worldwide. Contrary to about three decades ago when cancer was more prevalent in the developed world, the burden is significantly shifting to the developing countries. ${ }^{1}$

Cancer is the second most common disease in India responsible for maximum mortality with about 0.3 million deaths annually. This is primarily due to the poor availability of preventive, diagnostic and therapeutic measures for this disease.

Studies have revealed that cancer prevalence not only vary from country to country but also among different population groups within the same country. As a result, global statistics may not accurately represent many of the developing nations such as India. Therefore, it is necessary to understand the epidemiology and demographics of cancer in a particular locality so that the healthcare system can function more effectively. ${ }^{2}$ In this regard, regional or institution based studies have an added significance. This study is to evaluate the histopathological spectrum of female malignancies with a motive to understand the prevalent trends of this complex disease.

\section{Materials and Methods}

This was a retrospective and prospective study to determine the histopathological spectrum of malignancies in females, carried out in the Department of Pathology at Dr. D.Y. Patil Medical College, Hospital and Research Center, Pimpri, Pune-411018. An Institutional Ethics Committee Clearance (IECC) was obtained before the start of the study. All female patients with lesions that were histopathologically confirmed as malignancy were included while benign lesions were excluded from the study.

The histopathological findings of 1016 malignant tumors in female patients were studied over a period of three years. Clinical details such as signs and symptoms, local and systemic examination, radiological findings and important laboratory investigations like tumor markers, if performed, were noted. Immunohistochemical report and any other ancillary test results, wherever available, were studied and recorded.

Specimens sent to the Department of Pathology for HPE, were carefully examined and processed as per standard protocol. Special stains like PAS, reticulin and IHC were done wherever necessary.

Histopathology report of each patient was studied carefully. The test results were analysed using standard statistical methods. Study results and observations were analysed, tabulated and compared with the literature on evidence based medicine. 


\section{Results}

Total of 1016 cases of malignant lesions affecting females were included in our study. Majority of the patients in the study were in age group of 40 to 69 years $(70 \%)$, this was closely followed by $24.4 \%$ cases between 50 and 59 years and $20.6 \%$ cases between 40 and 49 years of age. Only $14(1.4 \%)$ cases were younger than 20 years and $113(11.1 \%)$ cases were in age group of more than 70 years (Chart 1$)$.

Approximately $50 \%$ of these cases involved the breasts and female reproductive organs. The five most commonly involved systems were: reproductive, gastrointestinal system, oral cavity, pharynx \&salivary glands, the skin and respiratory system (Table 1).

More than $50 \%$ cases of breast malignancies in the study group were in the age group of 40-59 years with a mean age of 52.96years. The majority of these cases infiltrating duct carcinomas (IDC) accounting for $90.7 \%$ of the cases. Other common types were mucinous carcinoma, malignant phylloides tumor, medullary carcinoma and infiltrating lobular carcinoma (Table 2).Radiological findings amongst these patients revealed $62 \%$ of the breast malignancies to be BIRADS category 4 followed by category $5(35 \%)$ and category $3(2 \%)$ (Chart 2). 162 cases had undergone immunohistochemical studies which revealed 63\% luminal, 19\% HER2 rich and $18 \%$ triple negative type malignancies (Chart 3).

$80 \%$ of the reproductive system malignancies were between 40 and 70 years of age with a mean age of 52 years. Cervix (58\%) was the commonest site for primary malignancy in the reproductive system followed by ovary $(22 \%)$, uterine corpus $(19 \%)$ and vulva $(1 \%)$ (Table 1).

More than $50 \%$ of cases of cervical malignancies were between the age 40 and 59 years with mean age of 52.0 years. Squamous cell carcinoma was the most prevalent cervical malignancy, accounting for $108(94 \%)$ cases, followed by adenocarcinoma (3\%), neuroendocrine carcinomas $(2 \%)$ and undifferentiated endocervical sarcoma (1\%) (Table 3).

Approximately $70 \%$ of primary malignancies of ovary were between 40 and 70 years of age. Majority of the ovarian malignancies were surface epithelial tumors (77\%) followed by germ cell tumors (14\%) and sex cord stromal tumors (9\%). Serous adenocarcinoma accounted for $37 \%$ of these cases followed by mucinous adenocarcinoma $(21 \%)$ and transitional cell carcinoma (12\%). (Table 3)

More than $80 \%$ of patients with uterine corpus malignancies in the study group were over 50 years of age. Majority of these cases were adenocarcinomas (79\%). Squamous cell carcinoma, malignant mixed mullerian tumor and myometrial sarcoma were the other histopathological types (Table 3). There were 2 cases of squamous cell carcinoma of the vulva.

Gastrointestinal system malignancies were mostly between 50 and 69 years of age (79) with a mean age of
55 years. Colorectal carcinomas were the commonest primary malignancies of the digestive system followed by esophagus $(25 \%)$ and stomach $(22 \%)$ (Table 1$)$.

More than $70 \%$ of colorectal malignancies were diagnosed in patients aged 50 years and above with mean age of 56.6 years. Most of the primary colorectal carcinomas were adenocarcinomas $(67 \%)$ followed by mucinous adenocarcinomas (28\%), signet-ring cell carcinomas (3\%) and one case of squamous cell carcinoma(Table 4). Squamous cell carcinoma was the commonest type of esophageal carcinoma (92\%), followed by adenocarcinoma (5\%) and adenosquamous carcinoma (3\%) (Table 4).

Adenocarcinoma (intestinal/ diffuse type) was the commonest primary gastric malignancy accounting for $72 \%$ of the cases. Other histopathological types were signet-ring cell carcinoma (22\%), mucinous adenocarcinoma (3\%), squamous cell carcinoma (3\%) (Table 4).

Adenocarcinoma (57\%) was the predominant type of anal canal malignancy. One case each of mucinous adenocarcinoma, squamous cell carcinoma and malignant melanoma was also present (Table 4). One case each of adenocarcinoma appendix and malignant gastrointestinal stromal tumor was also noted.

$64 \%$ of the patients with oral cavity and oropharyngeal malignancies were between 50 and 69 years of age with mean of 55 years. Malignancies of oral cavity and oropharynx accounted for the majority number of cases $(51.4 \%)$ followed by tongue and the major and minor salivary glands which accounted for 29 and $8 \%$ cases respectively (Chart 4 ). Out of the 8 cases of salivary gland malignancies in the study group, there were three cases each of mucoepidermoid and squamous cell carcinoma and two cases of adenoid cystic carcinoma; all other malignancies in this group were squamous cell carcinomas.

$66 \%$ cases of skin and appendage malignancies were between 40 and 70 years of age with mean of 55 years. Squamous cell carcinoma was the most common diagnosis $(59 \%)$ followed by basal cell carcinoma (19.5\%), malignant melanoma (19.5\%) and a single case of trichilemmal carcinoma.

Most malignancies of respiratory system were between 60 and 69 years of age (46\%) with a mean age of 56 years. Lung and pleura accounted for more than $50 \%$ of cases, followed by larynx and trachea $(32 \%)$ and nose, nasopharynx and para-nasal sinuses (14\%). Histopathological spectrum of lung and pleural malignancies showed adenocarcinomas $(66 \%)$ to be the commonest tumor followed by squamous cell carcinoma (24\%) and malignant mesothelioma (10\%) (Chart 5).

There was a total of 28 cases of hepatobiliary malignancies with mean age of 54.5 years. The gall bladder and cystic duct accounted for $68 \%$ of these malignancies while $32 \%$ were in liver. There were 18 cases of gall bladder adenocarcinoma and 1 case of adenocarcinoma of cystic duct. Hepatocellular 
carcinomas (8) were the commonest lesion in the liver followed by cholangiocarcinoma (1).

$56 \%$ cases of urinary system malignancies were between 50 and 70 years of age with mean age of 59 years. Malignancies of the urinary bladder and kidney accounted for $56 \%$ and $44 \%$ cases respectively. The most prevalent histopathological type of malignancies involving the urinary system were the transitional cell carcinomas which accounted for more than half of the cases in this group. Renal cell carcinoma (9 cases), adenocarcinomas ( 1 case) and squamous cell carcinoma (1 case) were the other tumors (Chart 6).

The mean age for patients with thyroid malignancies was 43 years. There were a total of 28 cases of malignancies diagnosed in thyroid gland out of which the majority were diagnosed as papillary carcinoma (75\%) followed by medullary (11\%), follicular carcinoma (7\%) and insular carcinoma (7\%).

The mean age for soft tissue malignancies was 43 years. The commonest diagnosis was liposarcomas which accounted for $22 \%$ of the cases followed by rhabdomyosarcoma (13\%) and leiomyosarcoma (9\%) (Table 5).

Approximately $60 \%$ of primary malignancies of the CNS and eye occurred in patients less than 50 years of age with mean age of 39 years. Malignant glial tumors accounted for the majority of the cases of malignancies of the CNS. Among the glial malignancies, 6 cases were of glioblastoma grade IV, 4 cases of astrocytoma grade II, 3 cases each of astrocytoma grade III and anaplastic oligodendroglioma. Both the cases of ocular malignancy were retinoblastomas. There were 7 cases of metastatic tumors to the CNS (Table 6).

A bimodal age distribution was seen in cases of lymphoma (Chart 7). The majority of lymphomas were Non Hodgkin's lymphomas (22 cases) with only two cases of Hodgkin's lymphoma.

Out of 5 cases of bone, joint and cartilage malignancies, osteosarcoma and chondrosarcoma accounted for one case each while three cases were metastatic tumors to the bone.

32 cases were diagnosed as metastatic malignant tumors with unknown primaries. The commonest site of metastasis was the lymph node and CNS which accounted for 7 cases each. These were followed by other common sites like soft tissue (6 cases), liver (5 cases), bone (3 cases), omentum and peritoneum (3 cases).

Table 1: Distribution of cases according to Anatomical Site involved study group

\begin{tabular}{|l|l|c|c|}
\hline S. No. & \multicolumn{1}{|c|}{ Site Distribution } & Number of cases (n) & Percentage \% \\
\hline 1 & $\begin{array}{l}\text { Oral cavity, Oropharynx, Hypopharynx and } \\
\text { Salivary Glands }\end{array}$ & 105 & 10.3 \\
\hline 2 & Gastrointestinal System & 145 & 14.3 \\
\hline a & Esophagus & 37 & 3.9 \\
\hline b & Stomach & 32 & 3 \\
\hline c & Small intestine & 3 & 0.2 \\
\hline d & Appendix & 1 & 0.1 \\
\hline e & Colon and rectum & 58 & 5.7 \\
\hline f & Anal Canal & 7 & 0.7 \\
\hline g & Periampullary & 6 & 0.6 \\
\hline h & Others & 1 & 0.1 \\
\hline 3 & Hepatobiliary System & 28 & 3 \\
\hline 4 & Respiratory System & 37 & 3.6 \\
\hline 5 & Bones, Joints, Articular cartilage & 2 & 0.2 \\
\hline 6 & Skin & 46 & 4.5 \\
\hline 7 & Soft tissue & 26 & 2.6 \\
\hline 8 & Breast & 301 & 30 \\
\hline 9 & Reproductive system & 198 & 19.4 \\
\hline a & Cervix & 115 & 11.3 \\
\hline b & Ovary & 43 & 4.2 \\
\hline c & Uterine Corpus & 38 & 3.7 \\
\hline d & Vulva & 2 & 0.2 \\
\hline 10 & Urinary tract & 25 & 2.5 \\
\hline 11 & Eye \& Central nervous system (CNS) & 18 & 1.7 \\
\hline 12 & Thyroid \& other Endocrine Glands & 29 & 2.7 \\
\hline 13 & Lymphoma \& Hodgkin's Disease & 24 & 2.2 \\
\hline 14 & Metastatic tumor with Unknown Primary & 32 & 3 \\
\hline & Total & 1016 & 100 \\
\hline & & & \\
\hline
\end{tabular}


Table 2: Histopathological spectrum of Breast malignancies in study group

\begin{tabular}{|c|c|c|c|}
\hline S. No & Type & No. of cases (n) & Percentage \% \\
\hline 1 & Infiltrating duct carcinoma & 275 & 91.4 \\
\hline 2 & Mucinous carcinoma & 8 & 2.6 \\
\hline 3 & Medullary carcinoma & 5 & 1.7 \\
\hline 4 & Malignant Phylloidestumor & 5 & 1.7 \\
\hline 5 & Lobular carcinoma & 3 & 0.9 \\
\hline 6 & Papillary carcinoma & 2 & 0.7 \\
\hline 7 & Micropapillary carcinoma & 2 & 0.7 \\
\hline 8 & Secretory carcinoma & 1 & 0.3 \\
\hline \multicolumn{2}{|c|}{ Total } & 301 & 100 \\
\hline
\end{tabular}

Table 3: Histopathological spectrum of ovarian, cervical and uterine malignancies.

\begin{tabular}{|l|c|c|}
\hline \multicolumn{1}{|c|}{ Histopathological diagnosis } & No. of cases (n) & Percentage \% \\
\hline Ovary & 16 & 37 \\
\hline Serous adenocarcinoma & 9 & 21 \\
\hline Mucinous adenocarcinoma & 5 & 12 \\
\hline Transitional cell carcinoma & 4 & 9 \\
\hline Granulosa cell tumor & 3 & 7 \\
\hline Dysgerminoma & 2 & 5 \\
\hline Immature teratoma & 2 & 5 \\
\hline Endometroid adenocarcinoma & 1 & 2 \\
\hline Mixed Germ cell tumor & 1 & 2 \\
\hline Malignant mixed mulleriantumor & 43 & 100 \\
\hline Total & & \\
\hline Cervix & 108 & 94 \\
\hline Squamous cell carcinoma & 4 & 3 \\
\hline Adenocarcinoma & 2 & 2 \\
\hline Neuroendocrine carcinoma & 1 & 1 \\
\hline Undifferentiated Endocervical sarcoma & 115 & 100 \\
\hline Total & & \\
\hline Uterine corpus & 30 & 79 \\
\hline Adenocarcinoma & 3 & 8 \\
\hline Squamous Cell Carcinoma & 3 & 5 \\
\hline Malignant mixed mulleriantumor & 2 & 100 \\
\hline Myometrial sarcoma & 38 & \\
\hline Total & & \\
\hline
\end{tabular}

Table 4: Histopathological spectrum of gastrointestinal tract malignancies

\begin{tabular}{|l|c|c|}
\hline \multicolumn{1}{|c|}{ Type } & No of cases (n) & Percentage \% \\
\hline Esophagus & & \\
\hline Squamous cell carcinoma & 34 & 92 \\
\hline Adenocarcinoma & 2 & 5 \\
\hline Adenosquamous carcinoma & 1 & 3 \\
\hline Total & 37 & 100 \\
\hline Gastric & 23 & \\
\hline Adenocarcinoma (intestinal/ diffuse type) & 7 & 22 \\
\hline Signet-ring cell Carcinoma & 1 & 3 \\
\hline Mucinous Adenocarcinoma & 1 & 3 \\
\hline Squamous cell carcinoma & 32 & 100 \\
\hline Total & & \\
\hline Colorectal & 39 & 67 \\
\hline Adenocarcinoma & 16 & 28 \\
\hline Mucinous Adenocarcinoma & 2 & 3 \\
\hline Signet-ring cell carcinoma & 1 & 2 \\
\hline Squamous cell carcinoma & 1 & \\
\hline
\end{tabular}




\begin{tabular}{|l|c|c|}
\hline Total & 58 & 100 \\
\hline Anal canal & & \\
\hline Adenocarcinoma & 4 & 57.1 \\
\hline Mucinous adenocarcinoma & 1 & 14.3 \\
\hline Squamous cell carcinoma & 1 & 14.3 \\
\hline Malignant Melanoma & 1 & 14.3 \\
\hline Total & 7 & 100 \\
\hline
\end{tabular}

Table 5: Histopathological diagnosis of Soft Tissue malignancies

\begin{tabular}{|l|c|c|}
\hline \multicolumn{1}{|c|}{ Type } & No of cases (n) & Percentage \% \\
\hline Liposarcoma & 7 & 22 \\
\hline Rhabdomyosarcoma & 4 & 13 \\
\hline Leiomyosarcoma & 3 & 9 \\
\hline Dermatofibrosarcomaprotuberans (DFSP) & 2 & 6 \\
\hline Malignant Fibrous Histiocytoma & 2 & 6 \\
\hline Malignant Peripheral Nerve Sheath Tumor & 2 & 6 \\
\hline Myxofibrosarcoma & 1 & 3 \\
\hline Malignant spindle cell sarcoma unspecified & 5 & 16 \\
\hline Secondary tumor deposits & 6 & 19 \\
\hline Total & 32 & 100 \\
\hline
\end{tabular}

Table 6: Histopathological spectrum of malignancies involving CNS and Eyes

\begin{tabular}{|l|c|c|}
\hline \multicolumn{1}{|c|}{ Type } & No. of cases (n) & Percentage \% \\
\hline Astrocytoma Grade II & 4 & 16 \\
\hline Astrocytoma Grade III & 3 & 12 \\
\hline GlioblastomaMultiforme Grade IV & 6 & 24 \\
\hline Anaplastic Oligodendroglioma Grade III & 3 & 12 \\
\hline Retinoblastoma & 2 & 8 \\
\hline Secondaries & 7 & 28 \\
\hline Total & 25 & 100 \\
\hline
\end{tabular}

Chart 1: Bar diagram showing Age distribution of cases in study group ( $n=1016)$

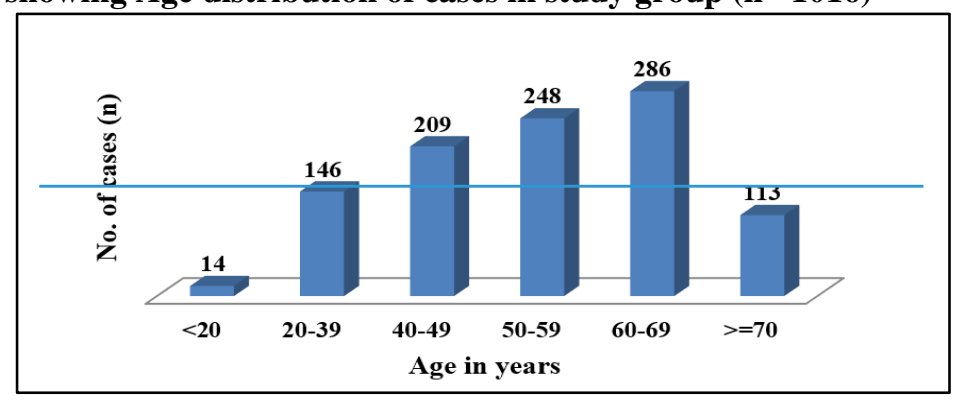

Chart 2: BIRADS categories of Breast malignancies in study group

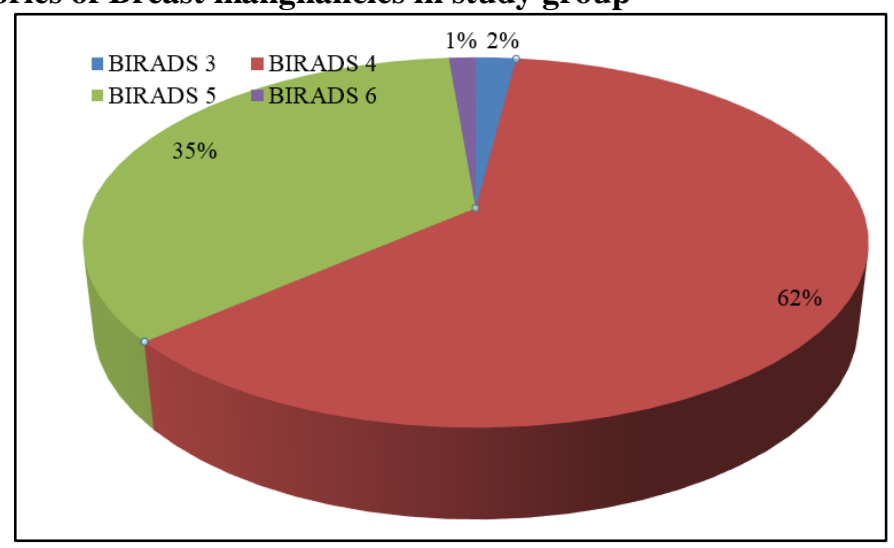


Chart 3: Immunohistochemical classification of breast malignancies in the study group ( $n=162)$

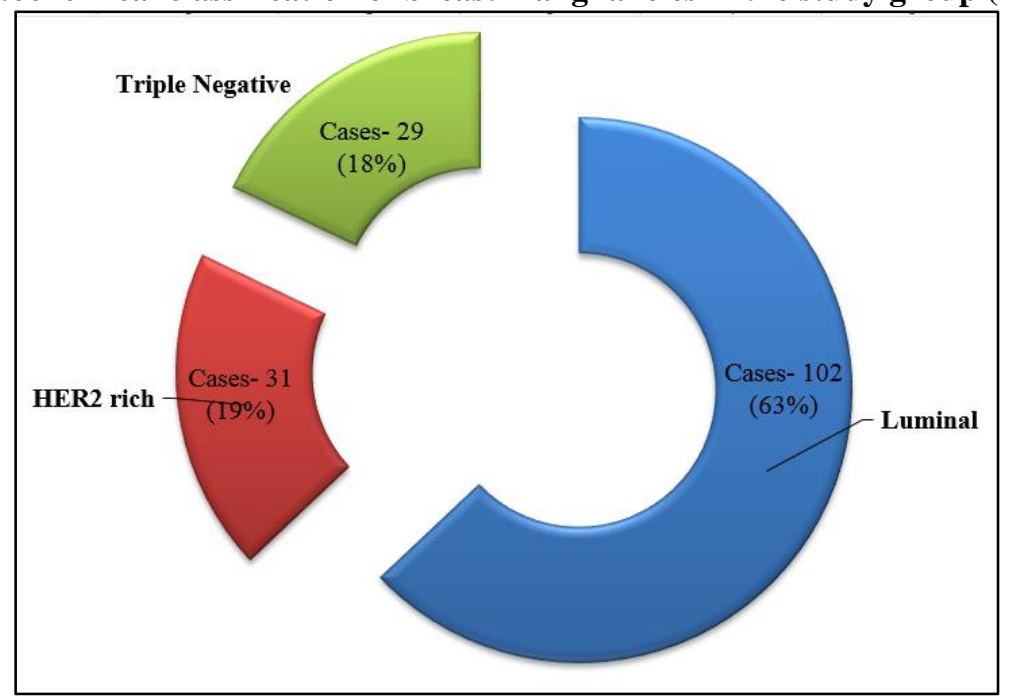

Chart 4: Distribution of cases in the Oral cavity, oropharynx, hypopharynx and salivary glands

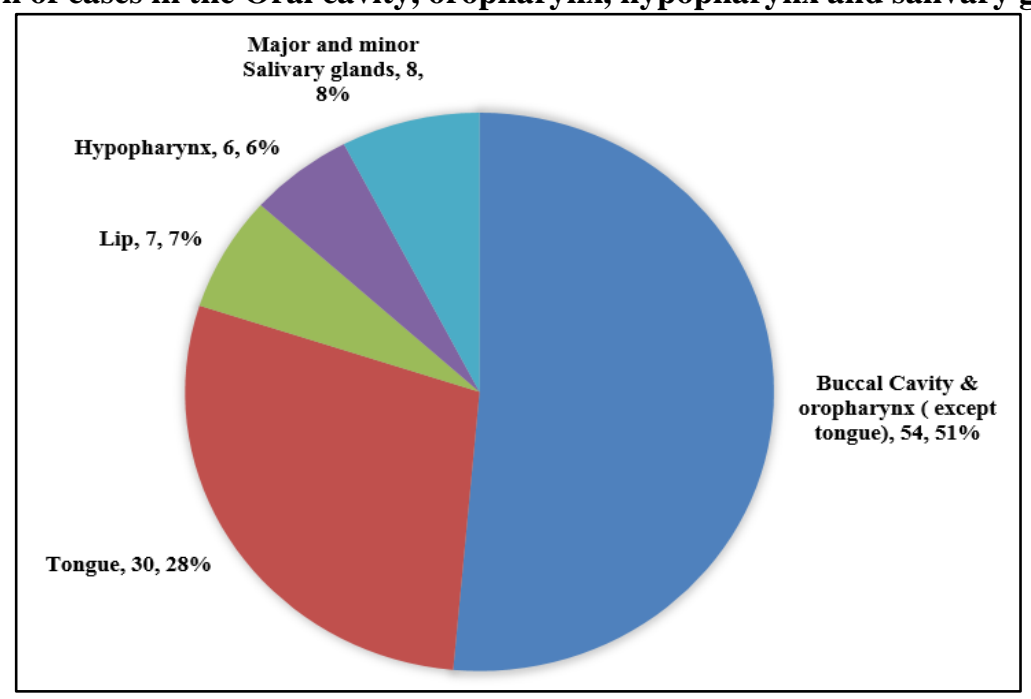

Chart 5: Histopathological spectrum of lung and pleura malignancies $(n=21)$

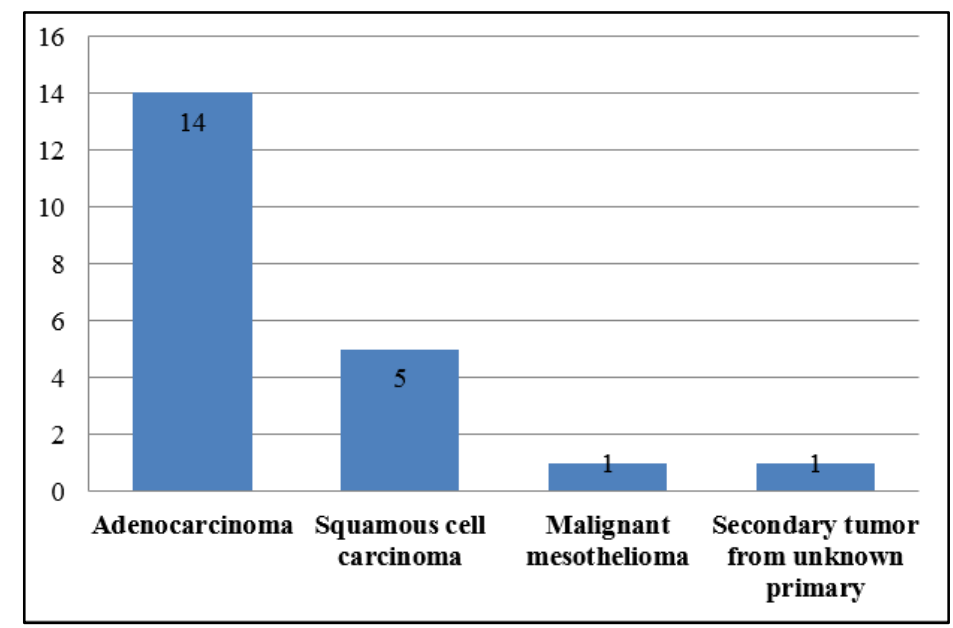


Chart 6: Histopathological spectrum of malignancies of the Urinary system $(n=25)$

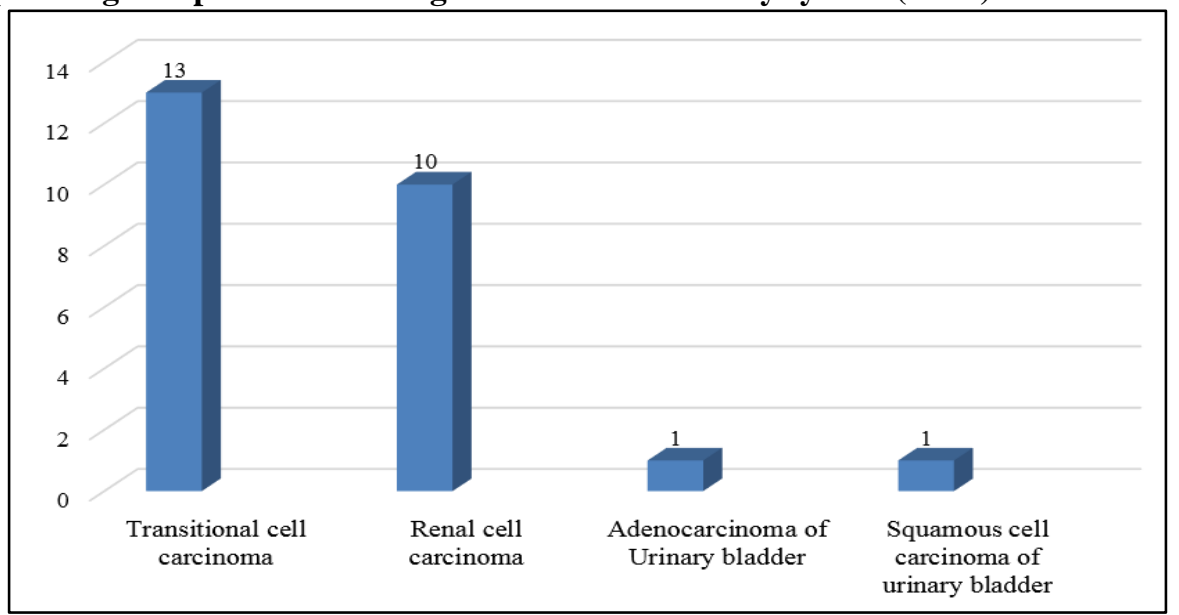

Chart 7: Line graph showing age distribution of lymphoma cases in the study group ( $n=24)$

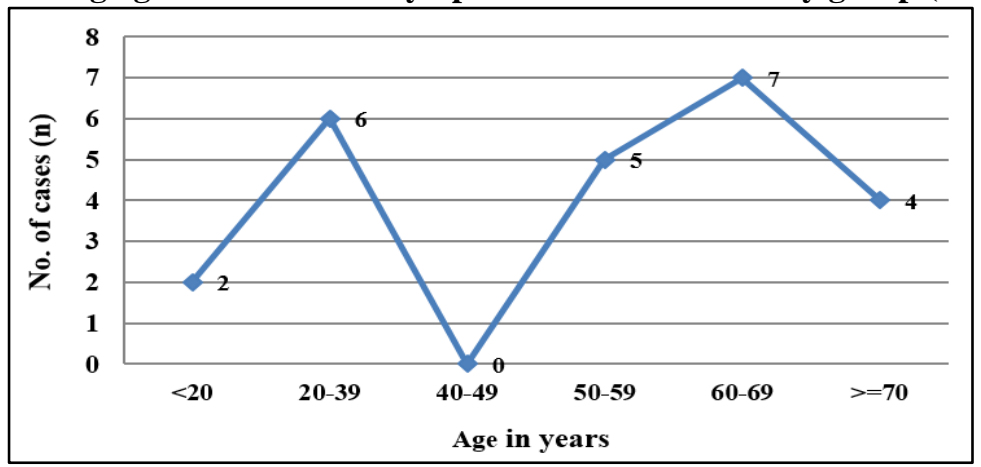

\section{Discussion}

Total 1016 cases were included in the study.

Age Distribution: Majority of the patients in the study were in age group of 40 to 69 years $(70 \%)$, this was closely followed by $24.4 \%$ cases between 50 and 59 years and $20.6 \%$ cases between 40 and 49 years of age (Chart 1). Sharma MK et al in 2012 studied 2324 cases of female malignancies in Chandigarh, India and observed that $73 \%$ of the cases were between 40 and 69 years. ${ }^{3} \mathrm{~A}$ study done by $\mathrm{Bal} \mathrm{M}$ et al had similar findings where $79 \%$ cases were between 40 and 69 years. ${ }^{4}$

Distribution According to Anatomical Site: The leading site for primary malignancy was the breast $(30 \%)$, followed by cervix $(11.3 \%)$, oral cavity $(8.9 \%)$, colorectum (5.8\%) and ovary (4.23\%)(Table 1). Sharma MK et al, reported breast to be the commonest site for female malignancies accounting for $33.3 \%$ of the cases. ${ }^{3,5}$ Agarwal KH and Rajderkar SS studied 941 cases of female cancers in Miraj, Maharashtra and reported cervix $(22.1 \%)$ to be the commonest site followed by breast (13.1\%). ${ }^{6}$ According to the WHO, the breast is the commonest site for malignancy among females, globally. ${ }^{7}$ Such variations in the distribution of site of malignancies can be attributed to differences in sample size, demographics, risk factor prevalence and access to healthcare systems. Our study also emphasises on the growing menace of oral cavity and colorectal cancers.
Rampant use of tobacco and its products especially among the female population may explain the rise in oral cavity cancers.

Increased number of colorectal cancers can be attributed to the adoption of westernised dietary habits with increased intake of meat and animal fat products. Access to colonoscopic examination and early detection of malignancy in colonoscopy guided biopsy specimens is probably another reason.

Breast: There were 301 cases of breast malignancies with mean age of 52.96 years. Similar observations were noted in few other earlier studies where mean age ranged between 53.39 and 60 years. ${ }^{8-10}$

A comparative analysis of histopathological diagnosis was done with other studies, all of whom observed that IDC was the most common type of breast malignancy ${ }^{8,11}$ However, Berg et al observed a decrease in the proportion of IDC (67.9\%) and also increased prevalence of infiltrating lobular carcinomas $(6.3 \%) .^{12}$ Though the prevalence of malignant phylloides tumor was less in other studies; a slightly higher prevalence rate was observed in our study as well as study done by Mudholkar VG et al. ${ }^{8}$

Majority of breast cancers were in BIRADS category $4(62 \%)$ followed by category $5(35 \%)$, category $3(2 \%)$ and category $6(1 \%)$. BIRADS category 3 lesions are defined as lesions which are probably 
benign on mammography. However, in ours as well as in earlier studies, it was observed that a BIRADS 3 lesion can be malignant on HPE and so such lesions need to be assessed by FNAC or trucut biopsies. ${ }^{13}$

Considering its high prevalence, impetus should be placed on early detection of breast malignancies, by promoting self breast examination and mass screening programmes with triple assessment for all breast lumps. IHC studies of 162 breast malignancy cases showed majority to be luminal type (63\%) followed by HER2 rich $(19 \%)$ and triple negative cancers $(18 \%)$. Ghosh J et al, in 2011 , observed $51.2 \%$ breast cancers to be Luminal type, $29.8 \%$ were Triple negative and $19 \%$ were HER2 rich. ${ }^{14}$

Reproductive System: Majority of the reproductive system malignancies involved cervix followed by ovaries and uterine corpus which is also corroborated by a study by Sharma RG et al. ${ }^{5}$

Cervical malignancies in our study group had a mean age of 52 years. Gumpeny $\mathrm{N}$. et al in Visakhapatnam, Andhra Pradesh, India, observed maximum number of cases $(29 \%)$ between 41 and 50 years of age. ${ }^{15}$ Similar finding was also reported by Lakshmi V and co-workers, in Tamil Nadu, India and found $39 \%$ patients to be between 41 and 50 years of age. ${ }^{16}$ Squamous cell carcinoma was the most prevalent histopathological type followed by adenocarcinoma and neuroendocrine carcinomas. Previous studies have also reported squamous cell carcinoma to be the commonest histopathological type, accounting for more than $90 \%$ of the cases. Deshpande JD et al, and Agrawal KH and Rajderkar SS in their studies have reported cervical cancer to be the commonest malignancy among females in western Maharashtra; however it ranks second in our study. ${ }^{17,6}$ Whether this difference indicates a decrease in the incidence of cervical malignancies or a relative increase in the number of breast carcinoma cases requires further investigation. A major factor contributing to this discrepancy is the population sampled in the studies. Both the above studies have been conducted at places with a predominantly rural population where health awareness and access to healthcare system is often limited. Our study population mainly comprised of semi-urban and urban population, where the effects of cancer awareness and screening are much more effective. Widespread adoption of PAP smear screening technique has helped to detect precancerous lesions of cervix among the mass population before it turns malignant. This may help to explain the decrease in cervical cancer prevalence.

Ovary was the fifth most common site for malignancy with 43 cases. Approximately $70 \%$ of ovarian malignancy was between 40 and 70 years of age. Serous adenocarcinoma was the most common primary ovarian malignancy followed by, mucinous adenocarcinoma, transitional cell carcinoma, granulosa cell tumor and dysgerminoma. Mankar DV et al observed the maximum number of ovarian malignancies between 40 and 60 years of age. ${ }^{18}$ Kanitkar SN and coworkers at Dhule, Maharashtra, studied 14 cases of malignant ovarian lesions and observed serous adenocarcinoma $(42 \%)$ to be the commonest ovarian malignancy followed by mucinous adenocarcinoma (21\%), metastatic tumor $(21 \%)$ and dysgerminoma $(14 \%) .^{19}$

Histopathological analysis of uterine corpus cancer revealed adenocarcinoma in $79 \%$ cases followed by squamous cell carcinoma and malignant mixed mullerian tumor. This was similar to the findings of Sharma RG et al. ${ }^{5}$

Gastrointestinal System: Gastrointestinal cancer was the second most common organ system accounting for $14 \%$ of thecases with mean age of 55 years. Colon and rectum was the most frequent site followed by esophagus, gastric and anal canal (Table 1). In a study by Thakur RY et al in 2016 it was observed that $68 \%$ of digestive tract malignancies among females were colorectal adenocarcinomas. ${ }^{20}$ The mean age for colorectal cancer was 56 years. Adenocarcinoma was the most common histopathological type of malignancy in the colon and rectum accounting for $67 \%$ of these cases. Laishram RS et al in Manipur, India, observed that 52\% of female colorectal cancer patients were between 50 and 69 years of age. ${ }^{21}$ Parikh BJ et al in Gujarat, observed that $87 \%$ of the colorectal cancers among female patients were adenocarcinomas. $^{22}$

Study of esophageal malignancies revealed, squamous cell carcinoma to be the commonest histopathological type, accounting for $92 \%$ of cases which was followed by adenocarcinomas (5\%) and adenosquamous carcinoma (3\%)(Table 4$)$. Few studies have reported esophageal carcinomas to be the commonest GIT malignancies. ${ }^{5,6}$ This is in contrast to our present study where colon and rectum was the most prevalent site.

Among the Gastric malignancies, adenocarcinoma (intestinal/ diffuse type) was the commonest lesion accounting for $72 \%$ of the cases followed by signet-ring cell carcinoma $(22 \%)$, mucinous adenocarcinoma $(3 \%)$ and squamous cell carcinoma (3\%) (Table 4). Parikh BJ et al observed adenocarcinomas $(60 \%)$ to be the commonest histopathological type of gastric cancers followed by signet ring cell carcinoma (30\%). ${ }^{22}$ Another study from Maharashtra reported similar findings with adenocarcinoma $(50 \%)$ being the commonest gastric malignancy followed by equal percentage of signet ring cell and mucinous adenocarcinoma $(25 \%){ }^{20}$

Oral Cavity and Oropharynx: Oral cavity \& oropharynx was the third most common site of malignancies. These were all squamous cell carcinomas. Majority $(41 \%)$ of these patients were in the $7^{\text {th }}$ decade of life. Amongst these cases, 33\% involved the tongue, $8 \%$ involved the lips, and the buccal cavity and oropharynx accounted for $59 \%$ of the cases (Chart 4 ). Akram S et al. in 2013 observed a similar distribution of cases where buccal cavity and oropharynx accounted for 
$69 \%$ of the cases followed by tongue (24\%) and lip $(7 \%) .{ }^{23}$ Siddiqui MS et al in 2012 studied 214 cases in Bihar, India, and observed larynx (34\%) to be a more common site for head \& neck malignancies, as compared to the oral cavity \& oropharynx $(28 \%){ }^{24}$

Siddiqui MS et al and Akram S et al, had observed a comparatively younger age group $\left(5^{\text {th }}\right.$ decade $)$ presenting with these malignancies. ${ }^{23,24} \mathrm{The}$ increased exposure to risk factors like tobacco, betel quid, areca nut and its substitutes at a younger age may have been a reason for the early occurrence of these cancers in the past. However, health education and mass awareness campaigns may have had a positive impact in reducing these cancers among the youth, as observed in the present study. This fact has also been emphasised by Bhat SP and co-workers. ${ }^{25}$

Skin and its Appendages: Females with malignancies of skin and its appendages had a mean age of 55 years. Squamous cell carcinoma (59\%) was the commonest skin malignancy followed by basal cell carcinoma (20\%), malignant melanomas (20\%) and trichilemmal carcinoma (1\%). Bhagyalakshmi A and co-workers studied 2278 cases of cancer in both male and females and reported skin malignancies to be $8 \%$ of the total; with females accounting for $48 \%$ of these cases. Basal cell carcinoma (42\%) was the commonest skin cancer in these female patients followed by squamous cell carcinoma (32\%) and malignant melanoma (9\%). ${ }^{26}$ Another study reported skin malignancies to encompass $2 \%$ of all malignancies studied among females, 6 squamous cell carcinoma being the commonest histopathological type. ${ }^{5}$ This is in accordance with our own study. However, we found an increased proportion of malignant melanoma cases.

Respiratory Tract: Lung malignancies amounted to $2 \%$ of the entire study population followed by larynx (1.2\%). Bhagyalakshmi A et al in their study reported $0.5 \%$ prevalence of lung cancer which was less than what was observed in our study. ${ }^{26}$ Sharma RG and co-workers observed the prevalence of lung carcinoma and laryngeal carcinoma to be around 3 and $1 \% .^{5}$

The spectrum of lung and pleural malignancies revealed adenocarcinomas to be the commonest tumor followed by squamous cell carcinoma and malignant mesothelioma. Novaes FT and co-workers studied 240 cases of lung cancer in Brazil and reported squamous cell carcinoma (38\%) to be the commonest lung malignancy followed by adenocarcinoma (30\%) and neuroendocrine carcinoma (16\%). ${ }^{27}$ Sharma RG et al reported squamous cell carcinoma to be the commonest lung malignancy followed by small cell lung carcinoma and adenocarcinoma. $^{5}$

Hepatobiliary System: Primary malignancies of the hepatobiliary system comprised of a total of 28 cases, of which $68 \%$ involved gall bladder and cystic duct while the rest involved the liver (32\%). The mean age of these patients was 54 years. Majority of these malignancies were hepatocellular carcinomas $(57 \%)$ followed by metastatic carcinomas $(36 \%)$ and cholangiocarcinoma (7\%).Other studies have also reported similar histopathological spectrum of hepatobiliary malignancies among females. ${ }^{5,26}$

Urinary System: 25 cases of urinary system malignancies were noted out of which 14 cases $(56 \%)$ involved the urinary bladder and the rest involved the kidneys. The mean age of these patients was 59 years. In an earlier study, malignancies of the kidney were found to be slightly more common than those of the urinary bladder. ${ }^{5}$ Majority of the urinary system carcinomas were of the transitional cell type (52\%) followed by renal cell carcinoma (40\%), adenocarcinoma bladder (4\%) and squamous cell carcinoma bladder (4\%) (Chart 6).

Thyroid: The histopathological study of thyroid malignancies revealed papillary carcinoma to be the most common $(75 \%)$ followed by medullary carcinoma $(11 \%)$ and follicular carcinoma (7\%). In a previous study 56 cases of thyroid carcinoma among females were studied and observations similar to our study was made. ${ }^{26}$ Another study reported, follicular carcinomas (22\%) to be more common than medullary carcinoma (5\%) however papillary carcinoma was still the most prevalent type of thyroid malignancy. ${ }^{5}$

Soft Tissue: The histopathological spectrum of soft tissue malignancies revealed liposarcoma to be the commonest lesion followed by rhabdomyosarcoma and leiomyosarcoma (Table 5). In a study by Bhagyalakshmi A et.al. comprising of 44 cases, the most prevalent lesion was found to be malignant fibrous histiocytoma (MFH) which accounted for $25 \%$ of these cases. ${ }^{26} \mathrm{MFH}$ in our present study accounted for only $6 \%$ of soft tissue malignancies. Due to the advent of IHC and molecular studies, many cases of MFH are being classified into other subtypes. This has led to a decrease in the number of MFH cases; however, this is subject to availability of these techniques in the diagnostic setup.

Central Nervous System (CNS) and Eye: Altogether, CNS malignancies accounted for $2.3 \%$ of the total study sample. Majority of the primary CNS malignancies were found among patients of 20 to 39 years and 50 to 59 years of age, with the mean age being 39 years. The histopathological spectrum of CNS malignancies revealed glial tumors to be the commonest tumor type. Sen U et al in 2002 found CNS tumors to account for $1.3 \%$ of all malignancies among females. ${ }^{28}$ Our present study revealed a slightly higher percentage. The histopathological spectrum of CNS malignancies in our study is similar to that reported by Sharma RG and coworkers in 2014. ${ }^{5}$

Lymphoma: Lymphoma cases showed a bimodal age distribution with peaks in the groups of 20 to 39 years and 50 to 69 years (Chart 7). A similar finding has also been reported by Medeiros LJ and Grenier TC in 1995. ${ }^{29}$ Non Hodgkin's lymphoma accounted for $92 \%$ of these cases while rest were Hodgkin's lymphoma. 


\section{Conclusion}

This study is based on observation of the histopathological spectrum of 1016 malignant lesions among females in a Tertiary care hospital over a period of three years. Most malignancies occurred between $5^{\text {th }}$ and $7^{\text {th }}$ decade. Female reproductive system was the commonest organ system to be affected. Breast was the most common site for malignancy followed by cervix. Infiltrating duct carcinoma of the breast was the commonest histopathologic type of malignancy among females in the study group.

We conclude that in spite of many recently developed diagnostic modalities; histopathological examination has triumphantly withstood the test of time and remains the gold standard for the diagnosis of malignant lesions.

The successful implementation of any health programme needs the active and wholehearted participation of both the healthcare providers and the population at risk. Therefore, population based cancer awareness programmes, early detection and mandatory notification of cancer cases would go a long way in improving cancer management. Hospital based Cancer Registries should be established since they provide data which can prove to be an invaluable tool to understand this complex disease and plan effective remedial measures.

\section{References}

1. Jemal A, Siegel R, Ward E, Murray T, Xu J, Thun MJ. Cancer statistics 2007. CA Cancer J Clin. 2007;57:43-66.

2. Ali I, Wani WA, Saleem K. Cancer scenario in India with future perspectives. Cancer Therapy. 2011;8:56-70.

3. Sharma MK, Gour N, Pandey A, Wallia D, Kislay D. Epidemiological Trends of Cancer Morbidity at a Government Medical College Hospital, Chandigarh, India. Asian Pacific J Cancer Prev. 2012;13(7):3061-64.

4. Bal MS, Bodal VK, Kaur J, Kaur M, Sharma S. Patterns of Cancer: A Study of 500 Punjabi Patients. Asian Pac J Cancer Prev. 2015;16(12):5107-10.

5. Sharma RG, Kapoor R, Bang BA, Gurjar K. Spectrum of malignancies in Jaipur region (2004-2008). Indian J Cancer. 2014;51(1):45-53.

19. Kanthikar SN, Dravid NV, Deore PN, Nikumbh DB, Suryawanshi KH. Clinico-Histopathological Analysis of Neoplastic and Non-Neoplastic Lesions of the Ovary: A 3-Year Prospective Study in Dhule, North Maharashtra, India. J ClinDiag Res. 2014;8(8):4-7.

20. Thakur RY, Nikumbh DB, Swamy SY. Clinico Histopathological Overview of GIT Lesions in a Rural Hospital. Indian Journal of Pathology and Oncology. 2016;3(2);305-14.(129)

21. Laishram RS, Kaiho N, Shimray R, Devi SB, Punyabati P, Sharma DC. Histopathological Evaluation of Colorectal Carcinomas Status in Manipur, India. International Journal of Pathology. 2010;8(1):5-8.

22. Parikh BJ, Parikh SB. Histopathological Spectrum Of Gastrointestinal Tumours. Natl J Integr Res Med. 2016;7(2):14-7.
6. Agrawal KH, Rajderkar SS. Magnitude and leading sites of cancer in a Tertiary cancer care hospital of western Maharashtra. Natl J Community Med. 2011;2(3):443-7.

7. Causes of Death Ch 2. World Health Organization, The Global Burden of Disease: 2004 update. Geneva: WHO;2008.p.13.

8. Mudholkar VG, Kawade SB, Mashal SN. Histopathological Study of Neoplastic Lesions of Breast. Indian Medical Gazette. 2012:353-64.

9. Truong PT, Berthelet E, Lee J, Kader HA, Olivotto IA. The prognostic significance of the percentage positive/dissected axillary lymph nodes in breast cancer recurrence and survival in patients with one to three positive axillary lymph nodes. Cancer. 2005;103(10):2006-14

10. Lee AHS, Gillett CE, Ryder K, Fentiman IS, Miles DW, Millis RR. Different patterns of inflammation and prognosis in invasive carcinoma of the breast. Histopathology. 2006;48(6):692-701.

11. Srivastava V, Wahi K, Gupta AK, Mittal VP, Rajvanshi VS. Clinicopathological study of malignant breast neoplasms with special reference to cellular enzymatic activity. Ind J Cancer. 1976;13:220-6.

12. Berg JW, Hutter RV. Breast cancer. Cancer. 1995;75(1):257-69.

13. Mendez A, Cabanillas F, Echenique M, Malekshamran K, Perez I, Ramos E. Mammographic features and correlation with biopsy findings using 11-gauge stereotactic vacuum-assisted breast biopsy (SVABB). Ann Oncol. 2004;15(3):450-4.

14. Ghosh J, Gupta S, Desai S, ShetT, Radhakrishnan S, Suryavanshi $\mathrm{P}$ et al. Estrogen, progesterone and HER2 receptor expression in breast tumors of patients, and their usage of HER2-targeted therapy, in a tertiary care centre in India. Indian J Cancer. 2011;48(4):391-6.

15. Gumpeny N, Devi AN. Pattern of cervical lesions, with emphasis on precancer and cancer in a tertiary care hospital of southern India. Int J Res Med Sci. 2015;3(5):1122-4.

16. Lakshmi V, Muddegowda PH, Lingegowda JB, Konapur PG, Subramanian PM, Thamilselvi R. Retrospective histopathological analysis of cervical cancer: Our experience. Archives of Cytology and Histopathology Research. 2016;1(1):28-31.

17. Deshpande JD, Singh KK, Phalke DB. Profile of Cancer Cases at a Tertiary Care Level Teaching Hospital in Rural Western Maharashtra, India. Natl J of Community Med. 2012;3(4):607-11.

18. Mankar DV, Jain GK. Histopathological profile of ovarian tumours: A twelve year institutional experience. Muller J Med Sci Res. 2015;6:107-11.(126)

23. Akram S, Mirza T, Mirza MA, Qureshi M. Emerging patterns in clinico-pathological spectrum of Oral Cancers. Pak J Med Sci. 2013;29(3):783-7.

24. Siddiqui MS, Chandra R, Aziz A, Suman S. Epidemiology and histopathological spectrum of head and neck cancers in Bihar, a state of Eastern India. Asian Pac J Cancer Prev. 2012;13(8):3949-53.

25. Bhat SP, Bhat V, Permi H, Shetty KJ, Aroor R, Bhandary BSK. Oral and oropharyngeal malignancy: A clinicopathological study. IJPLM. 2015;1(1):OA1 (20 February 2015)

26. Bhagyalakshmi A, Venkatalakshmi A, Subhash R, Kumar SS. Patterns of cancer occurrence in a tertiary care centre. Int J Res Med Sci. 2016;4(6):2153-63.

27. Novaes FT, Cataneo DC, Ruiz Junior RL, Defaveri J, Michelin OC, Cataneo AJ. Lung cancer: histology, 
staging, treatment and survival. J Bras Pneumol. 2008;34(8):595-600.

28. Sen U, Sankaranarayan R, Mandal S, Ramanakumar AV, Parkin DM, Siddiqi M. Cancer patterns in eastern India: the first report of the Kolkata cancer registry. Int $J$ Cancer. 2002;100(1):86-91.

29. Medeiros LJ, Grenier TC. Hodgkin's disease. Cancer. 1995;75(1 Suppl):357-69.

How to cite this article: Gore C.R., Dey I, Kumar H, Shah K, Gulati I. Recent trends in histopathological spectrum of malignancies among females in western Maharashtra. Indian $\mathbf{J}$ Pathol Oncol. 2018;5(4):598-608. 